\title{
Reproducing the Proximal Femoral Anatomy: Large-Diameter Head THA
}

\author{
William G. Blakeney, Jean-Alain Epinette, \\ and Pascal-André Vendittoli
}

\section{Key Points}

Large Diameter Head THA

- Is defined as a bearing diameter $>36 \mathrm{~mm}$ and includes monobloc or dual-mobility femoral head designs.

- Allows supraphysiologic postoperative hip range of motion and return to unrestricted activities.

- Is a forgiving procedure, minimizing the risk of femoral neck impingement on the acetabular component rim.

- Dislocation rate is extremely low whatever the surgical approach.

W. G. Blakeney

Department of Surgery, CIUSSS-de-L'Est-de-L'Ilede-Montréal, Hôpital Maisonneuve Rosemont. 5415, Montréal, QC, Canada

Department of Surgery, Albany Health Campus, Albany, WA, Australia

J.-A. Epinette

Clinique Médico-chirurgicale,

Bruay la Buissière, France

e-mail: jae@orthowave.net

P.-A. Vendittoli $(\bowtie)$

Department of Surgery, CIUSSS-de-L'Est-de-L'Ilede-Montréal, Hôpital Maisonneuve Rosemont. 5415, Montréal, QC, Canada

Department of Surgery, Université de Montréal,

Montréal, QC, Canada
- Helps restore hip biomechanics, minimizing the requirement for surgical modifications linked to intraoperative stability.

- CoC THA has the potential to provide long-term implant survivorship with unrestricted activity, while avoiding implant impingement, liner fracture at insertion, and hip instability.

- With the recently reported low wear rate, Dual Mobility THA could be considered for a larger proportion of THA patients.

\subsection{Introduction}

There are many potential benefits to using largediameter femoral heads (LDHs, >36 $\mathrm{mm}$ ) in total hip arthroplasty (THA). They provide a supraphysiologic range of motion (ROM), which makes them more forgiving with regard to component positioning. This is of particular benefit to high-demand patients involved in manual work or with an active lifestyle. These are frequently young patients, in which the use of a hard-on-hard bearing also offers the promise of prosthetic longevity. The move toward large head ceramic-on-ceramic $(\mathrm{CoC})$ bearings 
ought to diminish the incidence of local adverse reaction to metal debris (ARMD) experienced with some LDH metal-on-metal (MoM) bearings.

\subsection{Hip Stability and Range of Motion}

Throughout the world, LDH has been increasingly used in THA mainly because of the perceived benefits of reduced dislocation risk. This has been demonstrated in a number of trials. A series of 1748 patients operated on with LDH THAs reported a dislocation rate as low as $0.05 \%$ at a mean follow-up of 31 months [1]. A retrospective review of all primary THAs performed by two experienced arthroplasty surgeons reported a significantly higher rate of dislocation in small-diameter head THAs $(1.8 \%, 10$ of 559) compared to the LDH group $(0 \%, 0$ of 248$)$ at a mean follow-up of 5 years [2]. Improved outcomes have also been seen in patients undergoing revision THA. A randomized trial demonstrated a significantly lower instability with only $1.1 \%$ dislocation risk in patients with larger heads (36 or $40 \mathrm{~mm}$ ) compared to $8.7 \%$ in those with small heads $(32 \mathrm{~mm})$ at a mean of 5 years post-surgery [3]. These results have been replicated in national joint registries $[4,5]$.

The reduced dislocation rate seen in $\mathrm{LDH}$ THAs is a result of many possible factors. Primarily, it is a result of the greater head-to-neck ratio and increased jump distance (Fig. 7.1). It has also been proposed that large heads may provide passive resistance to dislocation through a suction effect, preventing microseparation [6]. A large head fills the capsular void left by resection of the native femoral head and has an increased volume to displace, which may further resist dislocation. They may also be favorable for joint perception and proprioception.

LDHs increase the ROM of the hip before prosthetic impingement. Burroughs et al., in a biomechanical study, found that the effect of increasing the head-neck ratio on range of motion plateaued at $38 \mathrm{~mm}$. This was because the impingement was no longer on the prosthesis but extra-articular (soft
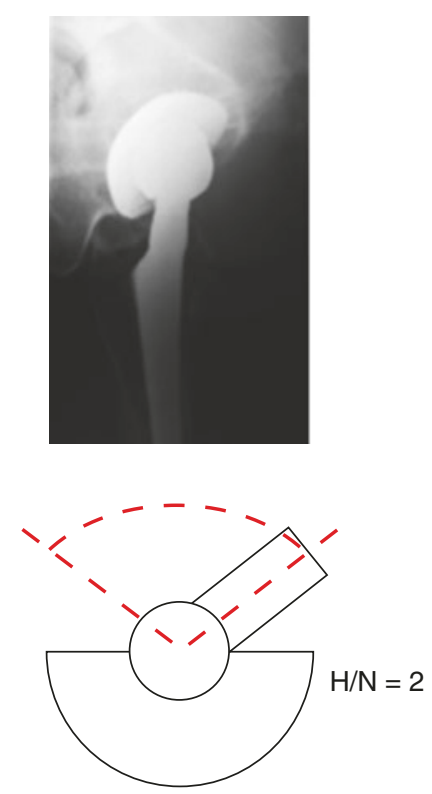

Small diameter THR
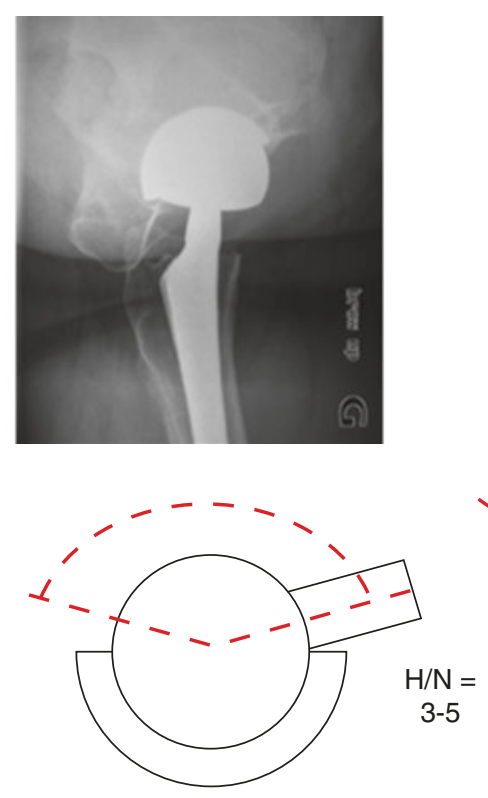

Large diameter THR
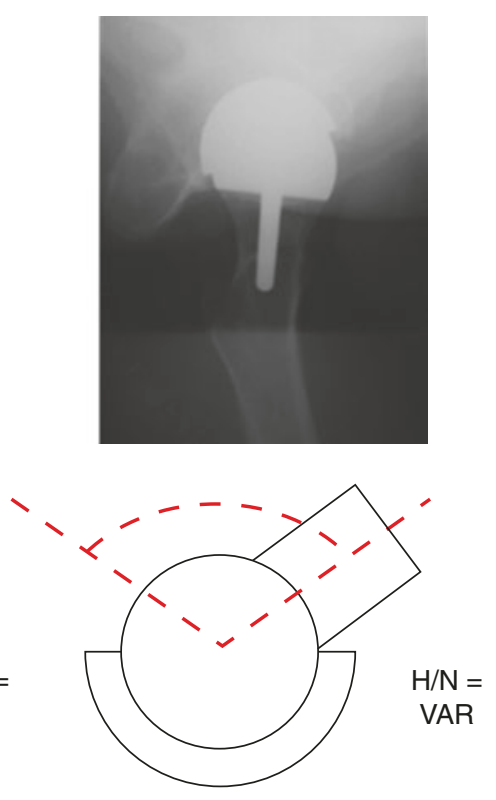

Resurfacing THR

Fig. 7.1 Different head-neck ratios and related arc of motion before component-component impingement for small diameter THA, LDH THA, and hip resurfacing 
tissue or bony) impingement, which was independent of head size [7]. Avoiding component impingement may be a significant advantage for hard bearings like ceramic. Contact between the metallic femoral neck and the ceramic liner has been associated with liner chipping, neck wear (metallosis), pain, and noise generation (squeaking) [8]. Moreover, Scifert et al. reported that with extra-articular contact, rather than impingement of the prosthetic neck on the liner, the moment resisting dislocation increased substantially (about fourfold larger) [9]. Cinotti et al. similarly found increased range of motion with larger head sizes and reported that the benefit of larger heads on ROM was even greater in mal-positioned acetabular components; thus, it is a more forgiving implant [10]. This is of importance, given the high number of patients with lumbosacral degeneration undergoing THA, and the known difficulties faced by the surgeon in optimally placing the acetabular component in this subset of patients at high risk of impingement and dislocation $[11,12]$.

Young and active patients frequently suffer from secondary OA associated with anatomical challenges, such as acetabular retroversion, hip dysplasia, femoral retroversion, Perthes deformity, and pistol-grip femur. These extreme anatomies may not be ideal for hip resurfacing procedures where anatomy correction is limited. In THAs, ideal component positioning for most advantageous ROM and wear may be limited by suboptimal primary fixation. Using LDH THAs helps the surgeon to manage these challenges.

Although the range of motion may plateau with increasing head size, the jump distance required for dislocations to occur will continue to increase. The jump distance is the amount of lateral translation of the femoral head center required for dislocation. The greater the head size, the greater is the jump distance required for dislocation. The jump distance, however, decreases with increasing offset of the center of rotation of the femoral head. This is of importance as the current designs of cups for LDH articulations are often truncated hemispheres of $\sim 160^{\circ}$ with offset of 3-4 mm. Increasing cup abduction and to a lesser degree anteversion also affect the jump distance, so an LDH will offset the risk of dislocation due to component malpositioning [13].

Micro-separation has been reported in vivo by many authors, who demonstrated that during the swing phase, the femoral head may not stay centered inside the cup. A metal-on-polyethylene (MoP) THA has a larger clearance between the femoral head and the polyethylene liner. Furthermore, polyethylene has reduced wettability that may result in less cohesiveness of the lubricating film, allowing hip separation to occur. A video fluoroscopy study has shown absence of micro-separation in large-head metal-on-metal (MoM) THAs compared to frequent microseparations in small-head MoP THAs [14]. Potential detrimental effects resulting from this micro-separation include premature wear and component loosening. It has also been linked to clicking and squeaking sounds coming from the hip. In a trial of 24 patients with a variety of tribological combinations, the only patient who did not generate sound was the only one not to experience femoral head micro-separation during gait [15]. CoC LDH THA with small clearance and broad contact surface may help to reduce or avoid bearing micro-separation during gait and improve muscle function and joint kinematics.

\subsection{Anatomical Reconstruction}

The other benefit to an $\mathrm{LDH}$ is in providing a more anatomical joint. By maintaining similar biomechanics as the native hip joint with regard to restoration of hip offset, leg length, and femoral head diameter on an individual case-by-case basis, it is thought the patient will have a more natural-feeling hip. Because of its intrinsic stability and low dislocation risk, surgeons performing LDH THA can tailor the patient's leg length and femoral offset to their individual anatomy without having to make adjustments or compromises to ensure hip stability. In the gait lab, it has been demonstrated that LDH THA restores the center of gravity and gait pattern to normal [16]. A number of studies have demonstrated that restoration of the femoral head diameter better restores normal gait parameters in comparison to conventional small head 
THAs $[17,18]$. LDH THA has been demonstrated to better restore hip ROM, compared to $28-\mathrm{mm}$ head THA and hip resurfacing [19]. In our experience, patients who have had a hip resurfacing and an LDH THA on the contralateral side, often prefer the more supple joint offered by the LDH THA.

As femoral head sizes have increased with a concomitant decrease in dislocations, surgeons have been removing more and more patient restrictions. A study of the Danish registry showed no increased risk of dislocation in a cohort of patients with $32 \mathrm{~mm}$ and $36 \mathrm{~mm}$ heads when immediately mobilized without restrictions following THA, compared to a historic cohort with $28 \mathrm{~mm}$ heads that had standard restrictions [20]. In our institution, using a posterior approach with LDH THAs, we have removed all postoperative restrictions, and review of our first 276 hips at a mean of 66.5 months (range 48.0-78.5) post surgery demonstrated a dislocation rate of $0 \%$ [21]. It also significantly simplifies the postoperative management of patients undergoing bilateral procedures or outpatient THA surgery. The need for patient education is considerably reduced and confidence in the hip is much higher.

Once the hip capsule is healed (2-3 months), we allow LDH THA patients to go back to unrestricted activities. At-risk activities, like kayaking, rock climbing, and skiing, are performed as with a natural hip. Professional activities are also resumed without limitations. Roof workers, plumbers, firemen, or policemen are allowed to go back to their original occupation. This lack of restrictions was not accepted by employers with the previously used smaller head diameter (28$32 \mathrm{~mm}$ ) MoP bearings. Furthermore, with the low wear rates of a $\mathrm{CoC}$ bearing, no limitation on the activity volume is imposed.

\subsection{Potential Concerns: Trunnionosis, ARMD, and Noise}

There are some potential disadvantages to using LDH THA. With the introduction of highly crosslinked polyethylene, concerns about volumetric wear in a polyethylene liner have proven unfounded on results to date. Clinically deleterious taper corrosion (or trunnionosis) has gained a lot of media attention with the well-documented problems, following the widespread introduction of LDH MoM THAs. A randomized trial reported higher serum metal ion levels in LDH MoM THAs compared to MoM hip resurfacings, suggesting that the problem is greater at the trunnion than at the articulation [22]. Though taper corrosion has been documented to occur with most head-neck material combinations and tribological combinations, reports of clinical sequelae were rare until the era of LDH MoM THAs. It is now understood to be associated with adverse local tissue reactions (ALTR), which may lead to clinical failure. It has been hypothesized that the small diameter of the trunnion in THAs, which was initially designed for a $28 \mathrm{~mm}$ head, may be more prone to corrosion due to increased frictional torque at the head-neck junction with a larger head. A conceivable solution is to increase the taper size for LDH. However, the degree to which LDH size is the cause of this problem is currently unknown. Implant retrieval as well as finite element analysis studies have identified multiple mechanical factors associated with the risk of trunnionism, including taper length, taper angle, surface finish, rigidity, and mixed alloys, which may result in corrosion. We compared whole blood titanium (Ti) ion levels at a minimum 1-year follow-up in 27 patients with unilateral primary LDH CoC THA with head sizes ranging from 36 to $48 \mathrm{~mm}$ using a Ti stem and acetabular component [23]. Mean Ti ion levels in patients with 36- to 40-mm head diameters (without Ti sleeve) was $2.3 \mu \mathrm{g} / \mathrm{L}$ and $1.9 \mu \mathrm{g} / \mathrm{L}$ for the 44- and 48-mm femoral head (with Ti sleeve). These Ti levels are low and probably related to unavoidable passive corrosion of implant surfaces. No patients presented clinical signs of ALTR.

LDH CoC bearings were introduced to reduce component impingement, increase stability, and optimize tribology without the associated problems seen in metal-on-metal bearings. With ceramic heads, metal ion release from the headneck junction is substantially lower than with metallic heads [23, 24]. The Australian joint reg- 
istry has reported a decreasing rate of revision at 5 years for increasing head size of a ceramic-onceramic bearing. A high revision rate of $4.7 \%$ is seen with heads of less than $28 \mathrm{~mm}$ compared to $3.3 \%$ for $32 \mathrm{~mm}, 2.8 \%$ for $36-38 \mathrm{~mm}$, and $2.6 \%$ for head size of $40 \mathrm{~mm}$ or greater [4]. This reduced revision rate is mainly a result of a reduced dislocation rate. At 1 year, the cumulative incidence of revision for dislocation is $2.0 \%$ for head sizes $28 \mathrm{~mm}$ or smaller compared to $0.4 \%$ for $32 \mathrm{~mm}, 0.3 \%$ for $36-38 \mathrm{~mm}$, and $0.1 \%$ for head sizes $40 \mathrm{~mm}$ or larger.

One problem that has been noted, specific to hard-on-hard bearings, is squeaking. McDonnell et al. reported on the Delta Motion Hip System (DePuy Synthes, Warsaw, IN, USA), the first LDH monoblock delta ceramic acetabular system (since withdrawn from production) [25]. They reported an overall squeaking incidence of $21 \%$ in 208 hips at a mean follow-up of 21 months. Goldhofer et al. reported an incidence of squeaking of $17 \%$ at 5-year follow-up [26], increased from $7 \%$ at 2 years [27]. There were, however, no significant differences with regard to patient satisfaction or clinical outcomes (Oxford Hip Score and Harris Hip Score) between the patients with squeaking and silent hips. In our institution, review of the first 276 hips using the Maxera (Zimmer, Warsaw, IN, USA; Fig. 7.2) LDH CoC

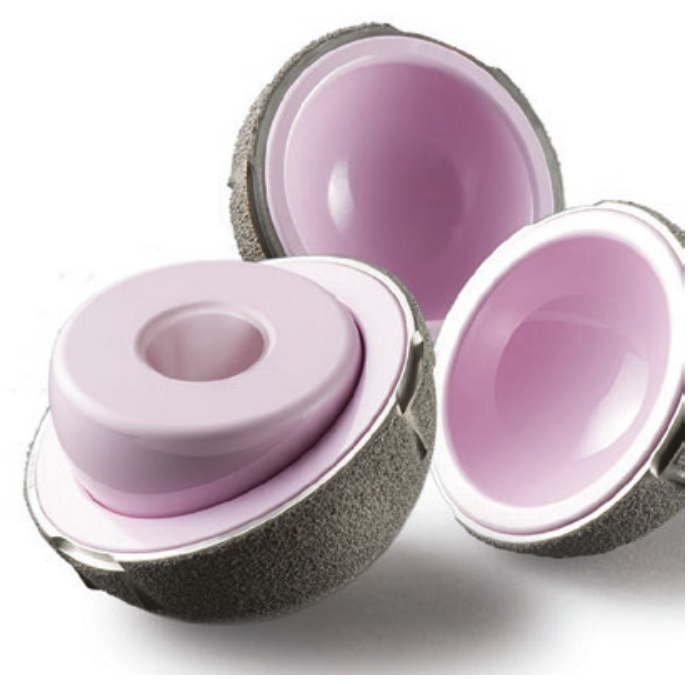

Fig. 7.2 LDH delta ceramic with the monoblock Maxera acetabular component hip system revealed a similar squeaking rate $(22.7 \%)$ [21]. Squeaking was significantly associated with younger age and more active patients (higher SF-12 PCS and UCLA scores). Greater femoral head size was also associated with increased squeaking. Despite the squeaking, functional scores and patient satisfaction were high. After 9 years of clinical use, we have replaced more than 2700 hips with $\mathrm{CoC} \mathrm{LDH}$ THA. No revisions were performed for component loosening, osteolysis, adverse reaction to metal debris (trunnionosis), implant fracture, or squeaking. There were five cases of early implant mobilization secondary to insufficient primary press fit fixation and four early postoperative dislocations treated with closed reduction without recurrence.

\subsection{LDH with Dual-Mobility Femoral Head}

Another hip component design that could be incorporated into an LDH option is the dual mobility (DM) articulation. This "old French invention," used since 1974 by Gilles Bousquet in Saint-Etienne (France), takes the double principle of a small articulation to minimize the problems of wear, coupled with a "big articulation" to stabilize the hip and prevent instability (Fig. 7.3) [28-30]. We know that DM implants are performing well for cases of primary THA with a high risk of dislocation (neurological patient, major muscle deficit, etc.) and complex prosthetic revisions. In comparison with conventional implants, DM cups can add an extra arc of movement before impingement of $30.5^{\circ}$ in flexion, $15.4^{\circ}$ in abduction, and $22.4^{\circ}$ in external rotation [31]. This high prosthetic stability is supported by the conclusions of a literature review done by Stroh et al. [32] that showed DM devices significantly reduce the risk of dislocation, both in primary arthroplasty $(0.1 \%$ for DM vs. $2-7 \%$ for fixed inserts) and in revision surgery (3.5\% for DM vs. $10-16 \%$ for fixed inserts). Since the early 2000s, improved DM implant designs have allowed a different assessment of the risk-benefit ratio, therefore creating potential new indications 

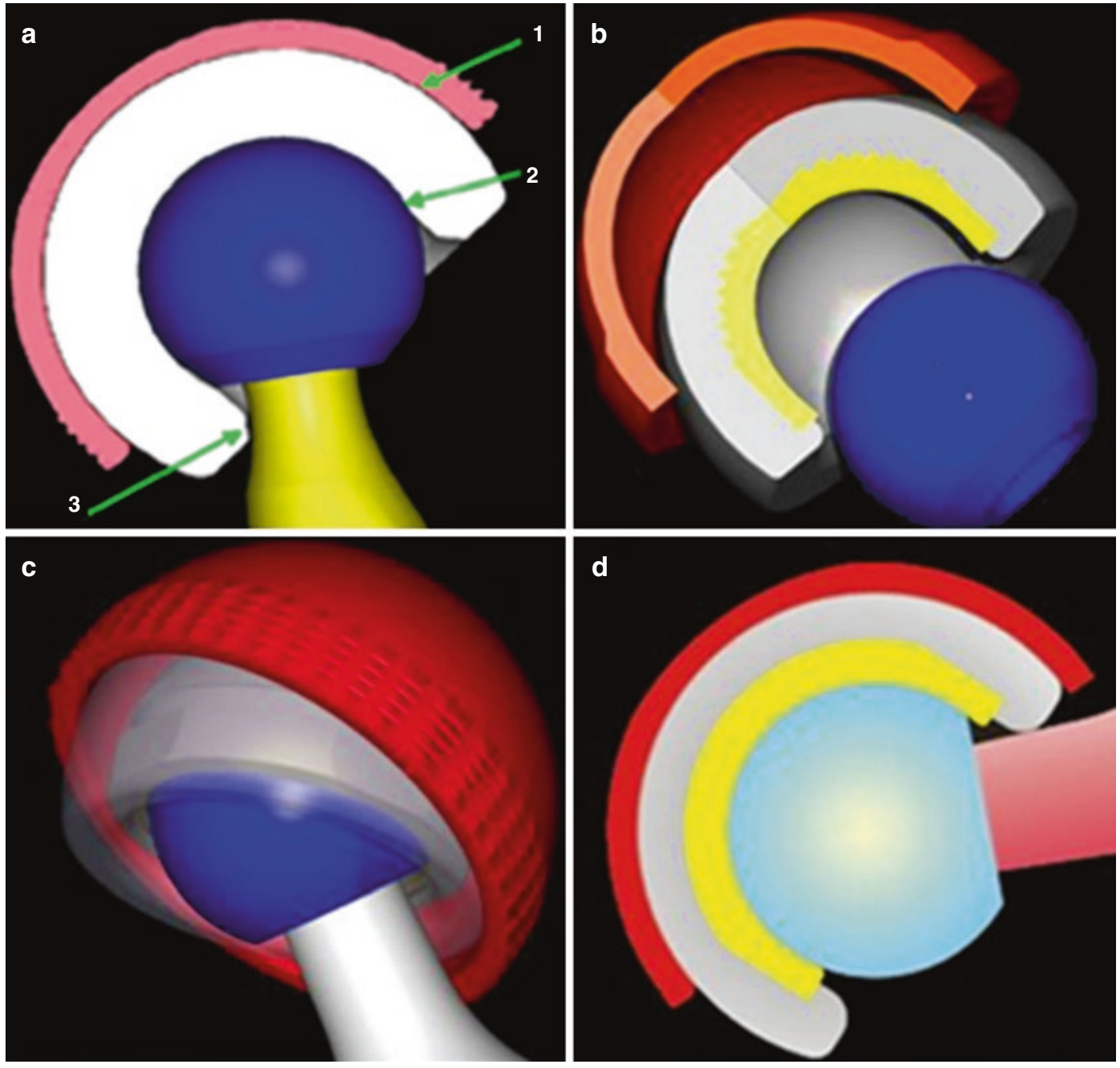

Fig. 7.3 The three articulating surfaces in DM cups: (a, b) demonstrate these three bearings as the large one (a.1) between the PE liner and metallic shell, the small one (a.2) between the femoral head and liner, and the socalled third articulation (a.3) between the femoral neck

for this DM solution [33]. The current implants' outer shell coatings now have optimized surfaces for bone fixation, resulting in comparable loosening rate to their fixed insert counterparts [34]. Second, better cup designs, smooth and round femoral necks, improved mechanisms for retention of the head in the mobile polyethylene liner, and new-generation polyethylene have almost eliminated the complication of intra-prosthetic dislocation (seen with early implants) and minimized wear. These improvements are expected to and the PE liner. (c) Illustrates the rotation of the PE liner upon contact with the femoral neck, while (d) shows the relationship during movements between the femoral neck, on the one hand, and first the liner, and second the rim of the metallic shell, on the other

continue in the long term, as well as for young and active subjects. Should we then endorse the extension of indications for DM to most of our THA patients? [35]

Encouraging early results, given this background of expanded indications, was presented at the 2015 EFORT congress (Prague). A total of 747 primary hips in 661 patients aged less than 55 years had excellent clinical results with mean Harris Hip Score scores of 93.4 points and a survivorship at 12.7 years with all-cause revision at 
98.9\% (0.976-1), with only three revisions (one early cup migration at 10 days, one neurotrophic pain at 2 years, and one anterior soft tissue impingement at 3 years). There was no dislocation, no instability, no loosening, no osteolysis or noticeable wear, and especially no intraprosthetic dislocation. A final element in the assessment of DM versus fixed insert bearings concerns the medico-economic aspect of this prosthetic option. Rehospitalizations for hip dislocations (even closed reduction), or for revisions in case of recurrent instability, have a significant overall cost in the national health budget. A recent French, national-level socioeconomic modeling (sample of 80,405 patients) looking at the comparative costs of these instability episodes, compared DM with fixed insert cups. They concluded that 3283 dislocations would be avoided per 100,000 patients if DM components were systematically used, with a potential annual gain for 140,000 prostheses of 39.6 million Euros [36]. What was demonstrated in France would probably be similarly observed on an international scale.

\subsection{LDH THA Summary}

LDH THAs either with monobloc or dualmobility femoral head have proven highly valuable in reducing the risk of dislocation. The supraphysiologic arc of motion provided by the large head-neck ratio makes it a forgiving procedure, leaving some room for imprecision by the surgeon and for suboptimal functional acetabular orientation, resulting from abnormal lumbopelvic kinematics. It may also permit a better reproduction of individual hip anatomy (femoral offset and leg length) for more physiological periprosthetic soft tissue tension that would likely favor more natural joint kinematics and optimize functional outcomes and patient satisfaction. Bilateral and outpatient procedures are simplified. It allows unrestricted ROM and return to usual activities and vocation. There is evidence that patients return to a more normal gait and have a greater ROM than conventional THAs. Patients often experience a much suppler hip, especially when preoperative contractures are present, with increased likelihood of having a forgotten hip. LDH THAs aim to better replicate normal human anatomy, which should lead to greater function and a more natural hip. Early results of LDH CoC bearings have been promising. Although there is a significant incidence of occasional squeaking, it does not appear to be bothersome to the patient. $\mathrm{CoC} \mathrm{LDH}$ has a reduced risk of early and late instability due to bearing wear. LDH with dualmobility femoral head is also very attractive because it has a lower cost, it does not produce noise and it is not linked with fracture. With the recently reported low wear rate, DM could be considered for a larger proportion of our THA patients, keeping LDH CoC bearings for a selected group of young and active subjects.

\section{Case Example}

A 40-year-old man, who had bilateral Perthes disease of the hips at a young age (Fig. 7.4), presents because of bilateral severe hip pain resistant to conservative treatment. He has worked as a fireman for the last 17 years and enjoys sporting activities like kayaking, cycling, and rock climbing. He has had to stop all leisure activities a year ago and has been off work for the last 3 months.

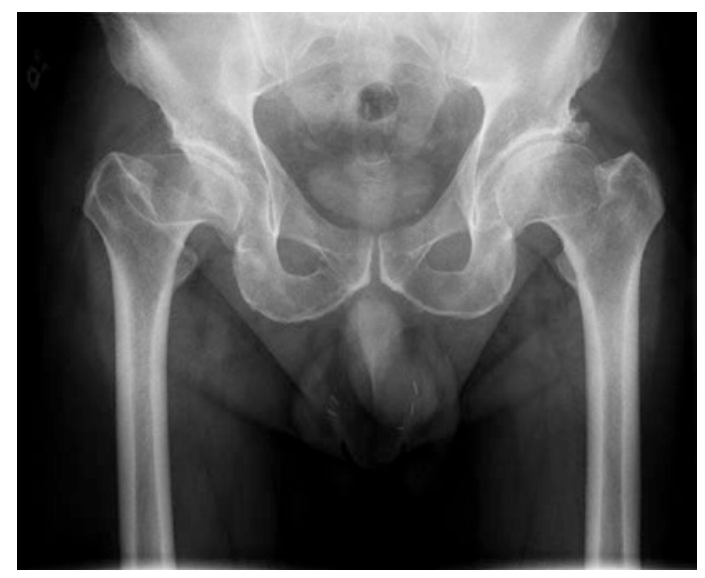

Fig. 7.4 Anteroposterior radiograph of the pelvis of a patient who had bilateral Perthes disease of the hips at a young age and secondary hip joint degeneration 


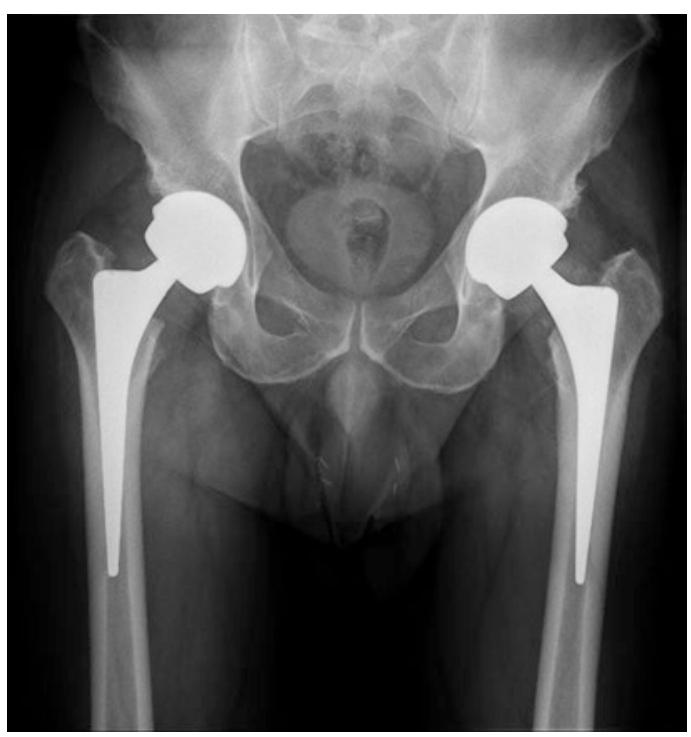

Fig. 7.5 Postoperative AP pelvis radiograph after bilateral CoC LDH THAs

He would like to resume his normal life as soon as possible.

We offered him bilateral CoC LDH THAs, performed in one stage through our standard posterior approach. Surgery was uneventful and took a total of $1 \mathrm{~h} 45 \mathrm{~min}$ including time to switch sides, with total blood loss of $450 \mathrm{cc}$ (Fig. 7.5). The patient stayed in hospital for 2 days. No range of motion restrictions were imposed. He was full weight-bearing without walking aids by 4 weeks and started stationary bike exercising. He resumed his work and leisure activities without restriction after 4.5 months. At 5-years follow-up, he is still very satisfied with his clinical results. He has heard some squeaking noise in his left hip on a few occasions but describes it as "not annoying." He considers his right hip as a natural or forgotten hip and the left one as an artificial hip without limitations.

\section{References}

1. Lombardi AV Jr, Skeels MD, Berend KR, Adams JB, Franchi OJ. Do large heads enhance stability and restore native anatomy in primary total hip arthroplasty? Clin Orthop Relat Res. 2011;469:1547-53.
2. Stroh DA, Issa K, Johnson AJ, Delanois RE, Mont MA. Reduced dislocation rates and excellent functional outcomes with large-diameter femoral heads. J Arthroplast. 2013;28:1415-20.

3. Garbuz DS, Masri BA, Duncan CP, et al. The frank Stinchfield award: dislocation in revision THA: do large heads ( 36 and $40 \mathrm{~mm}$ ) result in reduced dislocation rates in a randomized clinical trial? Clin Orthop Relat Res. 2012;470:351-6.

4. Author N. Australian Orthopaedic Association National Joint Replacement Registry. Annual report. Adelaide: AOA; 2017. https://aoanjrr.sahmri.com/ annual-reports-2017. Accessed 10 Oct 2017.

5. Malkani AL, Ong KL, Lau E, Kurtz SM, Justice BJ, Manley MT. Early- and late-term dislocation risk after primary hip arthroplasty in the Medicare population. $\mathrm{J}$ Arthroplast. 2010;25:21-5.

6. Peters CL, McPherson E, Jackson JD, Erickson JA. Reduction in early dislocation rate with largediameter femoral heads in primary total hip arthroplasty. J Arthroplast. 2007;22:140-4.

7. Burroughs BR, Hallstrom B, Golladay GJ, Hoeffel D, Harris WH. Range of motion and stability in total hip arthroplasty with 28-, 32-, 38-, and 44-mm femoral head sizes. J Arthroplast. 2005;20:11-9.

8. Elkins JM, O'Brien MK, Stroud NJ, Pedersen DR, Callaghan JJ, Brown TD. Hard-on-hard total hip impingement causes extreme contact stress concentrations. Clin Orthop Relat Res. 2011;469:454-63.

9. Scifert CF, Noble PC, Brown TD, et al. Experimental and computational simulation of total hip arthroplasty dislocation. Orthop Clin North Am. 2001;32:553-67, vii.

10. Cinotti G, Lucioli N, Malagoli A, Calderoli C, Cassese F. Do large femoral heads reduce the risks of impingement in total hip arthroplasty with optimal and non-optimal cup positioning? Int Orthop. 2011;35:317-23.

11. Malkani AL, Garber AT, Ong KL, et al. Total hip arthroplasty in patients with previous lumbar fusion surgery: are there more dislocations and revisions? J Arthroplast. 2018;33(4):1189-93.

12. Sing DC, Barry JJ, Aguilar TU, et al. Prior lumbar spinal arthrodesis increases risk of prosthetic-related complication in total hip arthroplasty. J Arthroplast. 2016;31:227-32 e1.

13. Sariali E, Lazennec JY, Khiami F, Catonne Y. Mathematical evaluation of jumping distance in total hip arthroplasty: influence of abduction angle, femoral head offset, and head diameter. Acta Orthop. 2009;80:277-82.

14. Komistek RD, Dennis DA, Ochoa JA, Haas BD, Hammill C. In vivo comparison of hip separation after metal-on-metal or metal-on-polyethylene total hip arthroplasty. J Bone Joint Surg Am. 2002;84-A:1836-41.

15. Glaser D, Komistek RD, Cates HE, Mahfouz MR. Clicking and squeaking: in vivo correlation of sound and separation for different bearing surfaces. J Bone Joint Surg Am. 2008;90(Suppl 4):112-20. 
16. Bouffard V, Nantel J, Therrien M, Vendittoli PA, Lavigne M, Prince F. Center of mass compensation during gait in hip arthroplasty patients: comparison between large diameter head total hip arthroplasty and hip resurfacing. Rehabil Res Pract. 2011;2011:586412.

17. Nantel J, Termoz N, Ganapathi M, Vendittoli PA, Lavigne M, Prince F. Postural balance during quiet standing in patients with total hip arthroplasty with large diameter femoral head and surface replacement arthroplasty. Arch Phys Med Rehabil. 2009;90:1607-12.

18. Nantel J, Termoz N, Vendittoli PA, Lavigne M, Prince F. Gait patterns after total hip arthroplasty and surface replacement arthroplasty. Arch Phys Med Rehabil. 2009;90:463-9.

19. Lavigne M, Ganapathi M, Mottard S, Girard J, Vendittoli PA. Range of motion of large head total hip arthroplasty is greater than $28 \mathrm{~mm}$ total hip arthroplasty or hip resurfacing. Clin Biomech (Bristol, Avon). 2011;26:267-73.

20. Gromov K, Troelsen A, Otte KS, Orsnes T, Ladelund $\mathrm{S}$, Husted H. Removal of restrictions following primary THA with posterolateral approach does not increase the risk of early dislocation. Acta Orthop. 2015;86:463-8.

21. Blakeney WG, Beaulieu Y, Puliero B, et al. Excellent results of large-diameter ceramic-on-ceramic bearings in total hip arthroplasty. Bone Joint $\mathrm{J}$. 2018;100-B:1434-41.

22. Garbuz DS, Tanzer M, Greidanus NV, Masri BA, Duncan CP. The John Charnley award: metal-on-metal hip resurfacing versus large-diameter head metal-onmetal total hip arthroplasty: a randomized clinical trial. Clin Orthop Relat Res. 2010;468:318-25.

23. Deny A, Barry J, Hutt JRB, Lavigne M, Masse V, Vendittoli PA. Effect of sleeved ceramic femoral heads on titanium ion release. Hip Int. 2018;28(2):139-44.

24. Hallab NJ, Messina C, Skipor A, Jacobs JJ. Differences in the fretting corrosion of metal-metal and ceramicmetal modular junctions of total hip replacements. J Orthop Res. 2004;22:250-9.

25. McDonnell SM, Boyce G, Bare J, Young D, Shimmin AJ. The incidence of noise generation arising from the large-diameter Delta motion ceramic total hip bearing. Bone Joint J. 2013;95-B:160-5.

26. Goldhofer MI, Munir S, Levy YD, Walter WK, Zicat $\mathrm{B}$, Walter WL. Increase in benign squeaking rate at five-year follow-up: results of a large diameter ceramic-on-ceramic bearing in total hip arthroplasty. J Arthroplast. 2018;33(4):1210-4.

27. Tai SM, Munir S, Walter WL, Pearce SJ, Walter WK, Zicat BA. Squeaking in large diameter ceramicon-ceramic bearings in total hip arthroplasty. J Arthroplast. 2015;30:282-5.

28. Fessy M. La double mobilité ; Maîtrise Orthopédique (152) 2006; http://www.maitrise-orthopedique.com/ articles/la-double-mobilite-86.

29. Guyen O, Pibarot V, Vaz G, Chevillotte C, BejuiHugues J. Use of a dual mobility socket to manage total hip arthroplasty instability. Clin Orthop Relat Res. 2009;467:465-72.

30. Grazioli A, Ek ET, Rudiger HA. Biomechanical concept and clinical outcome of dual mobility cups. Int Orthop. 2012;36:2411-8.

31. Guyen O, Chen QS, Bejui-Hugues J, Berry DJ, An KN. Unconstrained tripolar hip implants: effect on hip stability. Clin Orthop Relat Res. 2007;455:202-8.

32. Stroh A, Naziri Q, Johnson AJ, Mont MA. Dualmobility bearings: a review of the literature. Expert Rev Med Devices. 2012;9:23-31.

33. Epinette JA. Clinical outcomes, survivorship and adverse events with mobile-bearings versus fixedbearings in hip arthroplasty-a prospective comparative cohort study of 143 ADM versus 130 trident cups at 2 to 6-year follow-up. J Arthroplast. 2015;30:241-8.

34. Epinette JA, Beracassat R, Tracol P, Pagazani G, Vandenbussche E. Are modern dual mobility cups a valuable option in reducing instability after primary hip arthroplasty, even in younger patients? J Arthroplast. 2014;29:1323-8.

35. Blakeney WG, Epinette JA, Vendittoli PA. Dual mobility total hip arthroplasty: should everyone get one? EFORT Open Rev. 2019;4(9):541-7.

36. Epinette JA, Lafuma A, Robert J, Doz M. Costeffectiveness model comparing dual-mobility to fixed-bearing designs for total hip replacement in France. Orthop Traumatol Surg Res. 2016;102:143-8.

Open Access This chapter is licensed under the terms of the Creative Commons Attribution 4.0 International License (http://creativecommons.org/licenses/by/4.0/), which permits use, sharing, adaptation, distribution and reproduction in any medium or format, as long as you give appropriate credit to the original author(s) and the source, provide a link to the Creative Commons license and indicate if changes were made.

The images or other third party material in this chapter are included in the chapter's Creative Commons license, unless indicated otherwise in a credit line to the material. If material is not included in the chapter's Creative Commons license and your intended use is not permitted by statutory regulation or exceeds the permitted use, you will need to obtain permission directly from the copyright holder. 